\title{
Sobre o lugar de fala: localizações, silenciamentos e autorizações
}

About the place of speech: locations, silences and authorizations

\section{Camila Mendonça}

Mestra em Comunicação e Cultura (UFRJ); Bacharel em Estudos de Mídia (UFF) e em Comunicação Social - Rádio e TV (FACHA). É pesquisadora do Grupo de Estudos sobre Relações Raciais no Brasil (GERRB), promovido pelo Laboratório de Estudos em Comunicação Comunitária (LECC/ECO/UFRJ).

\section{Cíntia Albuquerque}

Mestranda em Comunicação e Cultura, na Linha de Mídias e Mediações Socioculturais, pelo Programa de Pós-graduação em Comunicação da UFRJ.

Submetido em 09 de setembro de 2018 Aceito em 04 de agosto de 2019

\section{RESUMO}

Publicado em 2017, o livro O que é lugar de fala?, de Djamila Ribeiro, tem sua centralidade no conceito de "lugar de fala", bastante citado nos últimos anos, especialmente em debates pela internet. Erroneamente confundido com representatividade, não diz respeito a quem pode ou não falar sobre quais assuntos, mas quais localizações sociais autorizam ou desautorizam à voz, promovendo, assim, a propagação ou o silenciamento de conhecimentos. Pela perspectiva do feminismo negro, a autora aponta a necessidade de pensar outros saberes para além das epistemologias hegemônicas, sendo a identidade um marcador fundamental para lembrar da inexistência de discursos neutros e universais, construídos nas relações de poder.

PALAVRAS-CHAVE: Djamila Ribeiro; lugar de fala; feminismo negro; identidade; poder. 


\section{ABSTRACT}

Published in 2017, Djamila Ribeiro's book O que é lugar de fala? has its centrality in the concept of "place of speech", frequently cited in recent years, especially in debates over the internet. Erroneously confused with representativeness, it does not concern who can or cannot talk about which subjects, but which social locations authorize or disown the voice, thus promoting the propagation or the silencing of knowledge. From the perspective of black feminism, the author points out the need to think other knowledges beyond hegemonic epistemologies, being identity a fundamental marker in reminding us that there are no neutral and universal discourses, constructed in the relations of power.

KEYWORDS: Djamila Ribeiro; place of speech; black feminist; identity; power.

\section{RESUMEN}

Publicado en 2017, el libro $O$ que é lugar de fala?, de Djamila Ribeiro, tiene su centralidad en el concepto de "lugar de habla", bastante citado en los últimos años, especialmente en debates por internet. Erroneamente confundido con representatividad, no se refiere a quién puede o no hablar sobre qué asuntos, pero qué ubicaciones sociales autorizan o desautorizan a la voz, promoviendo así la propagación o el silenciamiento de conocimientos. Por la perspectiva del feminismo negro, la autora apunta la necesidad de pensar otros saberes más allá de las epistemologías hegemónicas, siendo la identidad un marcador fundamental para recordar la inexistencia de discursos neutros y universales, construidos en las relaciones de poder.

PALABRAS CLAVE: Djamila Ribeiro; lugar de habla; feminismo negro; identidad; poder.

O que é lugar de fala?, da filósofa Djamila Ribeiro, é a primeira obra da coletânea Feminismos Plurais, cujo objetivo primordial é explicitar em linguagem didática e valor de mercado acessível importantes questões históricas que vêm reemergindo nos últimos anos. Aqui, "extrapolar" a academia e levar a um público leigo (em sua maioria, grupos socialmente marginalizados) discussões que fujam dos discursos dicotômicos (os quais tendem a se fechar, esvaziando-se), apresentando possibilidades de pensamentos plurais, é tarefa fundamental para a construção de debates mais honestos e inclusivos. Além disso, preza-se pela contribuição de autoras e autores negros e indígenas de diversas regiões do Brasil, sujeitos historicamente desautorizados à fala pelas narrativas dominantes. Ribeiro pontua que, por serem intrínsecas à nossa sociedade, é de suma importância não 
colocar as questões raciais como meros "recortes" ou "compêndios", como comumente ainda são no âmbito acadêmico, mas como essenciais para o rompimento de um discurso hegemônico que não privilegia a todos.

Para abrir a coleção, foi escolhida a temática do feminismo negro. Este, de acordo com a autora, ainda é comumente acusado de trazer cisões ou separações, sendo o contrário disto. "Ao nomear as opressões de raça, classe e gênero, entendese a necessidade de não hierarquizar opressões" (p. 13), ou seja, de não se criar uma "competição", elegendo quais opressões são "piores" ou "melhores" que as outras. Para apresentar alguns dos mais relevantes conceitos da temática, Ribeiro busca aporte teórico em intelectuais negras de diversas nacionalidades e épocas, como, Sueli Carneiro, Giovana Xavier, Lélia Gonzalez, Luiza Bairros, Sojourner Truth, Patricia Hill Collins, Angela Davis, bell hooks, Grada Kilomba, Linda Alcoff, Audre Lorde e Gayatri Spivak.

Ribeiro inicia o primeiro capítulo - "Um pouco de história" - com a proposta de falar dos percursos históricos intelectuais e de militância de mulheres negras antes de adentrar a questão do lugar de fala. Este tópico se centra em mostrar que são de longa data (e não um "modismo" da era da internet) as reflexões feitas por mulheres negras a respeito de suas especificidades, abafadas pelo chamado "feminismo clássico", o qual tende a trabalhar apenas a questão do gênero, tratando "mulheres" como uma categoria homogênea. A filósofa ressalta a produção intelectual e o ativismo de feministas negras já no período escravocrata ${ }^{1}$. 0 problema, então, não seria falta de ação por parte destas pessoas, mas de visibilidade em relação aos seus discursos e práticas de luta. A seletividade de pautas, escolhidas a partir dos pontos de vista de mulheres brancas de classes mais altas, criava uma "história única"2 para o feminismo e acabava por ocultar outras

\footnotetext{
${ }^{1}$ Ribeiro (pp. 20-1) traz como exemplo um dos mais famosos discursos da abolicionista, escritora e ativista norte-americana Sojourner Truth (1797-1883), Eu não sou uma mulher?, proferido em 1851, durante a Convenção dos Direitos da Mulher, na cidade de Akron, Ohio. Truth, como uma exescravizada, ao observar o tratamento diferenciado dado a negras e brancas em uma mesma sociedade, questiona a universalização da categoria "mulher", fazendo uma crítica de como o feminismo exclui as várias possibilidades de narrativas com uma ideia de suposta neutralidade baseada nas vivências de mulheres brancas de classes mais altas e na falta de compromisso por parte destas mesmas militantes com um feminismo realmente inclusivo e preocupado com os problemas existentes nos outros modos de ser mulher.

2 Um bom exemplo de fala sobre a temática da "história única", seus modos de construção e suas consequências, é a palestra da escritora nigeriana Chimamanda Ngozi Adichie, The danger of a single
} 
tantas existentes fora desse contexto. Ribeiro pontua que reivindicar a visibilidade da fala não é "querer aparecer" ou ser "separatista", como afirmam alguns grupos: o falar e ser ouvida da mulher negra é sinônimo da urgência de existir, há séculos solapada pela lógica patriarcal euro-cristã de quem pode falar e de quem deve ser calado.

A partir da questão da "fala autorizada", Ribeiro coloca a necessidade de refutação da epistemologia dominante, autojulgada como "neutra". Tal ideia sustentada pelo pensamento moderno ocidental, ao desembocar na noção do que seria $O$ conhecimento (portanto, o único válido, o correto), acaba por desconsiderar a infinidade de saberes existentes fora dessa esfera, perpetuando as opressões por meio de silenciamentos. A fim de restituir as humanidades negadas - e com elas, as narrativas negadas -, a autora defende a necessidade de pensar outros saberes, sendo o marcador da identidade fundamental para lembrar da inexistência de discursos neutros, pois, nas lógicas de poder, as identidades são construídas e utilizadas pelos detentores do mesmo para privilegiar ou oprimir. A respeito das críticas a este posicionamento, a filósofa explicita:

0 que se quer com esse debate, fundamentalmente, é entender como poder e identidades funcionam juntos a depender de seus contextos, e como o colonialismo, além de criar, deslegitima ou legitima certas identidades. Logo, não é uma política reducionista, mas atenta-se para o fato de que as desigualdades são criadas pelo modo como o poder articula essas identidades; são resultantes de uma estrutura de opressão que privilegia certos grupos em detrimento de outros (RIBEIRO, 2017, p. 31).

No capítulo seguinte, "Mulher negra: o Outro do Outro", Djamila Ribeiro discute a inferioridade da mulher negra tanto no campo do gênero quanto no da raça, por sofrer a subalternização por esses dois lados. A autora afirma que ainda há um "olhar colonizador" sobre os corpos negros femininos, seus saberes e produções, e que "para além de refutar esse olhar, é preciso que partamos de outros pontos" (p. 35). Assim, neste capítulo ela se debruça, principalmente, sobre teorias de autoras negras para analisar essa questão. Citando Simone de Beauvoir, a autora traz à tona

story, apresentada no evento TEDGlobal, em 2009. Disponível em: <https://www.ted.com/talks/chimamanda_adichie the_danger_of_a_single_story>. Acesso: 20 ago. 2018. 
a discussão proposta pela filósofa francesa de que a mulher é definida em comparação ao homem e pela visão do homem. Assim, ela é o Outro. Já a mulher negra seria, segundo a artista visual e escritora portuguesa Grada Kilomba, o Outro do Outro, por sofrer dupla inferioridade. Importante destacar que, para Beauvoir, ser inferior é ter sido tornada inferior.

A partir de Patricia Hill Collins, Ribeiro trabalha com o conceito de outsider within - forasteira de dentro - inserido no feminismo. Segundo Collins, dentro do movimento feminista, a mulher negra é forasteira por se definir politicamente como mulher negra e feminista, mas ser tratada de forma deslocada no movimento. "De dentro" por ser feminista, "forasteira" por ser negra. Dessa forma, a mulher negra está localizada no não-lugar; entretanto, ainda que este seja um espaço de dor, para Ribeiro, ele é também um espaço de potência. Em suma, a socióloga norte-americana critica a forma como se dá a universalização da mulher dentro do movimento feminista: "O não reconhecimento de que partimos de lugares diferentes, posto que experenciamos gênero de modo diferente, leva à legitimação de um discurso excludente, pois não visibiliza outras formas de ser mulher no mundo" (p. 51).

Caminhando para a temática central do livro, no capítulo "O que é lugar de fala?" Djamila Ribeiro começa a desvendar o conceito "lugar de fala" por meio de perspectivas adotadas por diferentes pensadores. Ainda que a origem do termo não seja precisa, a autora parte do pressuposto de que a discussão acerca do tema foi originada a partir do feminist standpoint (ponto de vista feminista). Para embasar o próprio argumento, Ribeiro se debruça sobre os estudos de Collins, cuja explicação sobre a teoria do ponto de vista feminista indica que as condições sociais de um indivíduo se sobrepõem às experiências individuais deles. Ou seja, são essas condições "que permitem ou não que esses grupos acessem lugares de cidadania" (p. 61). Dessa forma, seria interessante analisar os mecanismos de poder existentes e as categorias como gênero, raça, classe e sexualidade. Como analisa a autora, existe a tentativa, que pode partir tanto da sociedade quanto da mídia em geral, de individualizar o sujeito e descontextualizá-lo do grupo em que está inserido. Segundo Ribeiro, isso silencia e subalterniza as diferentes produções de saberes do grupo, impedindo-o de alcançar a legitimidade, ou seja, o reconhecimento. 
Para trazer o enfoque racial à discussão, a filósofa aponta que "essas experiências comuns resultantes do lugar social que ocupam impedem que a população negra acesse certos espaços" (p. 64). Assim, o apagamento do sujeito negro surge a partir da impossibilidade de acessar espaços como as universidade e os produtos midiáticos, já que o grupo social possui a sua própria voz, mas não há meios para que ela seja ouvida. É dessa forma que a autora relaciona lugar de fala com o feminist standpoint. A luta, nesse caso, é pelo direito da população negra à voz, e não à visão restritiva de que o racismo só pode ser debatido pelo ponto de vista do afrodescendente. $\mathrm{O}$ objetivo de Ribeiro, portanto, é eliminar a ideia de que lugar de fala é uma forma de autorização discursiva. Nesse contexto, a autora cita Grada Kilomba e a necessidade do grupo hegemônico - as pessoas brancas, nesse caso - de aprender a ouvir o grupo subalternizado. Kilomba "coloca essa dificuldade da pessoa branca em ouvir, por conta do incômodo que as vozes silenciadas trazem, do confronto que é gerado quando se rompe com a voz única" (p. 78).

Em vias de finalizar o livro, Ribeiro aborda no último capítulo, "Todo mundo tem lugar de fala", os argumentos para consolidar a importância de todos os sujeitos, de diferentes grupos, se implicarem nos discursos, utilizando aí a noção de Michel Foucault (1996). Isto é, "de não se pensar discurso como amontoado de palavras ou concatenação de frases que pretendem um significado em si, mas como um sistema que estrutura determinado imaginário social, pois estaremos falando de poder e controle" (p. 56). A autora desenha a essencial divisão entre representatividade e lugar de fala, já que ambos conceitos são, muitas vezes, confundidos. Citando o exemplo de uma travesti negra e um homem branco cisgênero, Ribeiro explica que esse homem não pode representar a travesti, mas possui o "lugar de fala" para teorizar a respeito dela. A filósofa considera que "falar a partir de determinados lugares é também romper com essa lógica de que somente os subalternos falem de sua localização, fazendo com que aqueles inseridos na norma hegemônica sequer se pensem" (p. 84).

Para Ribeiro, o mais importante é compreender que todos na sociedade possuem lugar de fala, já que todos fazem parte de um grupo e estão inseridos numa localização social. A partir desse ponto de vista, os indivíduos privilegiados socialmente podem se pensar, analisar as hierarquias criadas a partir desse lugar e 
compreender o impacto que essa localização resulta na existência dos grupos marginalizados na sociedade. Trabalhando novamente com o estudo de Grada Kilomba ${ }^{3}$, Djamila Ribeiro procura combater as hierarquias do discurso autorizado, em que certos saberes prevalecem sobre outros. Logo, esse combate pode ser interpretado como uma forma de luta contra a hegemonia. Dessa forma, a autora finaliza o livro relembrando que as discussões analisadas nele são um convite para a reflexão e não a imposição de uma epistemologia. A partir da obra, entende-se que Ribeiro procura tirar a voz do sujeito subalternizado do silenciamento a qual foi designada e romper com a hierarquia atualmente existente na produção de discursos.

\section{Referências bibliográficas}

Episódios do Sul: Massa Revoltante Vol. 2 - Conversa com Grada Kilomba. Disponível em: <https://www.youtube.com/watch?v=dGgzqLuXVns\&feature=share>. Acesso: 07 set. 2018.

FOUCAULT, Michel. A ordem do discurso. São Paulo: Edições Loyola, 1996.

RIBEIRO, Djamila. O que é: lugar de fala? Belo Horizonte: Letramento/ Justificando, 2017.

The danger of a single story. Chimamanda Ngozi Adichie, TEDGlobal 2009. Disponível em:

<https://www.ted.com/talks/chimamanda adichie the danger of a single story $>$. Acesso: 20 ago. 2018.

\footnotetext{
${ }^{3}$ Em 2016, Kilomba esteve na Mostra Internacional de Teatro de São Paulo (MITsp), onde realizou a palestra Descolonizando o conhecimento, na qual debateu sobre a hierarquia do discurso autorizado. A artista argumentou que os saberes e as ciências produzidas pelos intelectuais negros são considerados não-científicos, opiniões, experiências, enquanto as produções realizadas por intelectuais brancos são fatos, conhecimentos e ciências. Disponível em: $<$ https://www.youtube.com/watch?v=dGgzqLuXVns\&feature=share>. Acesso: 07 set. 2018.
} 